Article

\title{
Oxovanadium(V/IV) Complexes as Redox Mediators for Biofuel Cells: Physical, Magnetic, and Electrochemical Characterization, DFT and Molecular Docking
}

\author{
Natsuki Katsuumi ${ }^{1}$, Hiba Sehimi ${ }^{2,3, *}$, Sayantan Pradhan ${ }^{4}\left(\mathbb{D}\right.$, Sanyobi Kim ${ }^{1}$, Tomoyuki Haraguchi ${ }^{1}$ \\ and Takashiro Akitsu 1,* \\ 1 Department of Chemistry, Faculty of Science, Tokyo University of Science, 1-3 Kagurazaka, Shinjuku-ku, \\ Tokyo 162-8601, Japan; 1320529@ed.tus.ac.jp (N.K.); 1320543@ed.tus.ac.jp (S.K.); haraguchi@rs.tus.ac.jp (T.H.) \\ 2 Laboratory of Materials, Crystal Chemistry and Applied Thermodynamics, Faculty of Sciences of Tunis, \\ University of Tunis El Manar, El Manar II, Tunis 2092, Tunisia \\ 3 Faculty of Sciences of Gabes, University of Gabes, Erriadh Zrig City 6072, Tunisia \\ 4 Department of Chemistry, Jadavpur University, Kolkata, West Bengal 700032, India; sayan23us@gmail.com \\ * Correspondence: hiba.shimi@fst.utm.tn (H.S.); akitsu2@rs.tus.ac.jp (T.A.); \\ Tel.: +216-23966704 (H.S.); +81-3-5228-8271 (T.A.)
}

check for

updates

Citation: Katsuumi, N.; Sehimi, H.; Pradhan, S.; Kim, S.; Haraguchi, T.; Akitsu, T. Oxovanadium(V/IV) Complexes as Redox Mediators for Biofuel Cells: Physical, Magnetic, and Electrochemical Characterization, DFT and Molecular Docking. Compounds 2021, 1, 15-28. https:// doi.org/10.3390/compounds1010003

Academic Editor: Franco Bisceglie

Received: 6 February 2021

Accepted: 23 March 2021

Published: 29 March 2021

Publisher's Note: MDPI stays neutral with regard to jurisdictional claims in published maps and institutional affiliations.

Copyright: (c) 2021 by the authors. Licensee MDPI, Basel, Switzerland. This article is an open access article distributed under the terms and conditions of the Creative Commons Attribution (CC BY) license (https:/ / creativecommons.org/licenses/by/ $4.0 /)$.

\begin{abstract}
Based on the potential redox and catalytic ability of oxovanadium complexes, our goal was to characterize the physical properties of two such complexes to be used as mediators for laccase. Computational studies, TD-DFT calculations and docking simulations were performed to elucidate the interaction between laccase and the two anionic complexes (aquabis(oxalato)oxidovanadate(IV) (1) and bis(oxalato)dioxidovanadate(V)) (2), respectively. Electrochemical measurements carried out on anion complexes of $\mathbf{1}$ and $\mathbf{2}$ docked into laccase were compared to laccase alone, showing changes in oxidation-reduction potential and current value, especially with the oxovanadium anion of 2 . Since both internal tiny magnetic fields of ferromagnetic catalysts and external applied magnetic fields were found in previous investigations to constitute effective ways to improve the oxygen transfer rate, the magnetic susceptibility was measured. A valence change proneness was confirmed with higher valence for the oxovanadium anion of $\mathbf{2}$, which is in accordance with the electrochemical results.
\end{abstract}

Keywords: oxovanadium; complex mediator; biofuel cell

\section{Introduction}

The longstanding need for reliable sources of energy has produced an active interest in fuel cells. However, fuel cells' drawbacks, including high cost, use of precious metals, and extreme $\mathrm{pH}$ values, have necessitated the development of enzymatic biofuel cells (EBFCs). Enzymes represent a renewable alternative to replace expensive and rare metal catalysts, such as platinum or palladium, used in conventional fuel cells and can accomplish high catalytic turnovers under mild conditions $\left(20-40{ }^{\circ} \mathrm{C}\right.$ within a reasonable $\mathrm{pH}$ range of $5-8$ or even at neutral $\mathrm{pH}$ ) [1]. In addition, specific enzymes catalyze the same reactions as inorganic catalysts in fuel cells and may replace them in either the anode or the cathode, or both.

The first report of an enzymatic biofuel cell was published in 1964, and the topic has now been studied for approximately 50 years [2]. The most common cathode reaction in a biofuel cell is the electroreduction of oxygen to yield water; a reaction catalyzed mainly by multicopper oxidase enzymes [3], the laccases/bilirubin oxidases. Anode catalysts include hydrogenases/alcohol-dehydrogenases/glucose oxidase. Glucose/oxygen biofuel cells use an electron donor, glucose, fuel, an anode incorporating glucose oxidase to oxidize them, and a cathode incorporating laccase, which reduces oxygen to convert chemical energy into electrical energy [4] (Figure 1). This is based on the same principle whereby living 
organisms have enzymes that catalyze oxidation and reduction reactions, and convert the energy of redox reactions into bioenergy by catalytic functions [5].

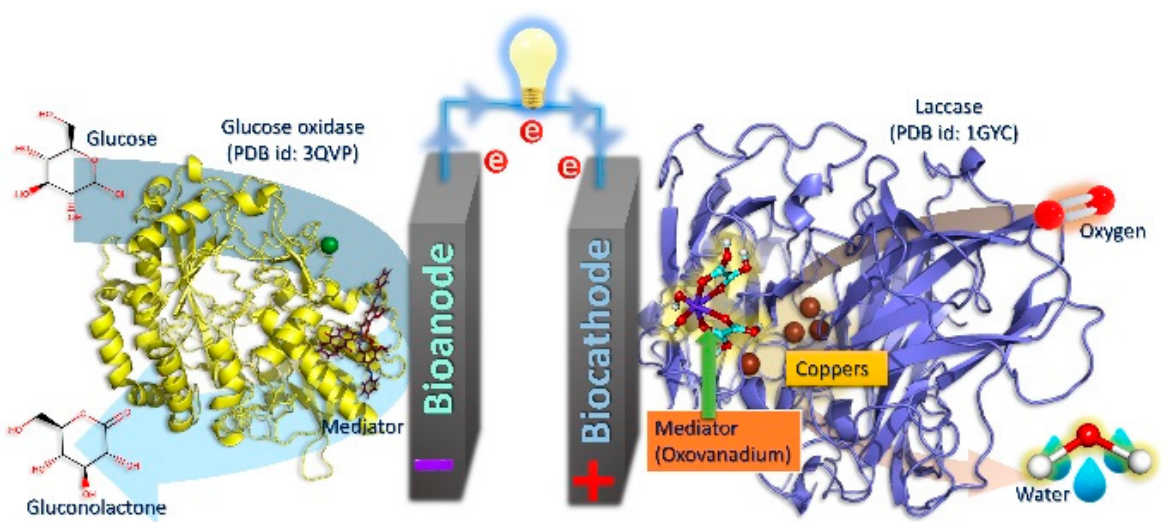

Figure 1. Schematic diagram of the reaction mechanism of a typical enzymatic biofuel cell.

Laccase found in the common polypore mushroom (Trametes versicolor) is an enzyme that is frequently used in the enzyme part of biofuel cells' cathode side. Its active center is formed by four copper ions [5], and it can catalyze the four-electron reduction to water without forming intermediate water-soluble peroxides. This multicopper oxidase accepts external electrons on $\mathrm{Cu}$-Type1, and reduces oxygen with $\mathrm{Cu}$-Type2/3 [6,7]. It is also known that a space (hydrophobic pocket) having a high affinity for a hydrophobic group exists near $\mathrm{Cu}$-Type1.

EBFCs offer the advantages of low environmental pollution, safe handling, easy miniaturization, and low fuel cost, but possess the disadvantages of low enzyme durability and low power consumption [8,9]. These cells' performance is markedly impeded by poor electron transfer between the enzyme catalysts and the electrode surfaces. In other words, the rate of electron transfer is among the main parameters that require improvement to optimize the performance of laccase-based biocathodes. Consequently, achieving a stable and efficient electrical contact between the electrode's surface and the enzyme active site remains critical in designing EBFC electrodes. In addition to improvement of direct electron transfer methods, numerous ways currently exist to improve efficiency and facilitate smoother electron transfer via mediators that relay electrons between the electrode and the enzyme. Mediators usually involve organic dyes or organometallic complexes dissolved in solution or immobilized on the electrode [10]. Nanoparticle mediators have low current density, while metal complex mediators possess a current density advantage [11].

Oxovanadium complexes have been used in various redox catalysts. For example, they exhibit bromoperoxidase activity by catalyzing the peroxidation bromination of phenol derivatives, and they achieve nuclease activity by nicking in supercoiled DNA [12]. They have also been shown to catalyze the oxidation of sulfides [13] and alcohols [14]. Some act as a redox mediator for the electrosynthesis of epoxides from olefinic compounds [15]. Moreover, some vanadyl complexes containing oxygen ligands (oxalate) showed similar activities to vanadium-containing bromoperoxidase $[16,17]$. However, to the best of our knowledge, no report yet exists on the use of redox active $\mathrm{V}=\mathrm{O}$ complexes as mediator metal complexes for mediated electron transfer in biofuel cells between the electrode and laccase.

It is presumed that the use of the redox or catalytic function of $\mathrm{V}=\mathrm{O}$ complexes [18] can exhibit a function as a catalyst and a function as a mediator. For such a purpose, and in continuation of our previous study on the use of spatial interactions in complexing laccases with various metal (Mn(II), Mn(III/II), Co(II), Ni(II), Cu(II), Zn(II)) complexes [11,19-23] and improving the ability of the complexes to reduce oxygen, two oxovanadium complexes $[24,25]$ were investigated in this work as potential mediator candidates. 


\section{Materials and Methods}

2.1. Synthetic Procedures

\subsubsection{General Information}

Chemicals of the highest available commercial grade (4-dimethylaminopyridine and 2,6-diaminopyridine from Tokyo Chemical Industry (Tokyo, Japan) and oxalic acid dihydrate and vanadium $(\mathrm{V})$ oxide from Wako (Osaka, Japan)) were used as received without further purification.

\subsubsection{Synthesis of $\mathbf{1}$ and $\mathbf{2}$}

The two oxovanadium complexes $\mathbf{1}$ and $\mathbf{2}$ were resynthesized based on methods described in the literature [24,25] (Scheme 1) with a slight modification of the reaction temperature at $373 \mathrm{~K}$.<smiles>O=C(O)C(=O)O</smiles>

1)<smiles>CN(C)c1ccncc1</smiles><smiles></smiles><smiles>[Te]C1CC1</smiles>

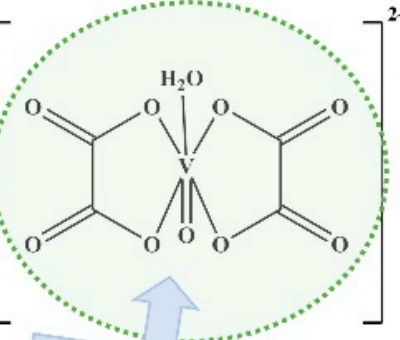
$2 \mathrm{II}_{2} \mathrm{O}$<smiles></smiles>

2) $100{ }^{\circ} \mathrm{C}, 15 \mathrm{~min}$<smiles>Nc1cccc(N)n1</smiles>

2) $100^{\circ} \mathrm{C}, 1 \mathrm{~h}$

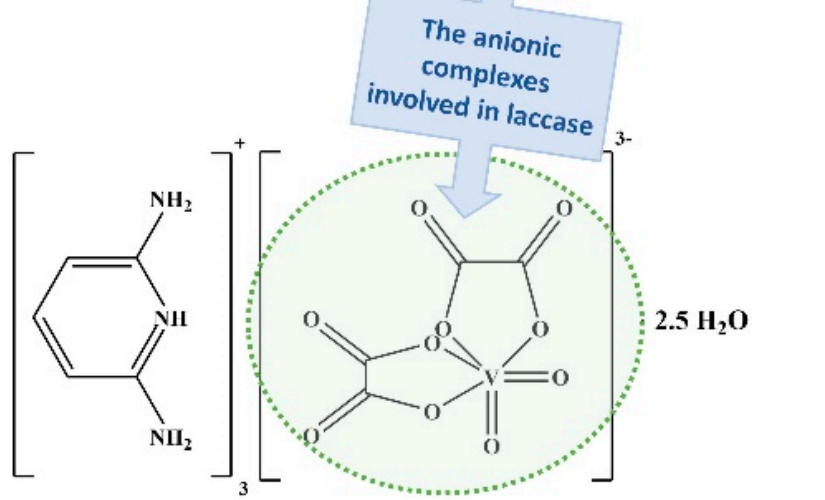

Scheme 1. Synthetic scheme of complex 1 (top) and complex 2 (bottom), highlighting the anionic complexes involved in laccase.

Both reaction mixtures for $\mathbf{1}$ and $\mathbf{2}$ were heated to $90^{\circ} \mathrm{C}$ to remove the ion-exchanged water used as a solvent to obtain solids (1: $0.2114 \mathrm{~g}, 77.9 \%$, green powder and 2: $0.12698 \mathrm{~g}$, $10.1 \%$, reddish brown powder).

Cell constants identical to those in the literature $[24,25]$ were confirmed by singlecrystal X-ray diffraction. To confirm the structures of complexes $\mathbf{1}$ and 2, infrared (IR), ultraviolet-visible (UV-vis), circular dichroism (CD) spectra, cyclic voltammograms, electron spin resonance (ESR), and superconducting quantum interference device (SQUID) spectra were measured.

\subsubsection{Docking of $\mathbf{1}$ and $\mathbf{2}$ with Laccase}

To observe the interactions between the two complexes and laccase, hybrid materials of complexes $\mathbf{1}$ and $\mathbf{2}$ with laccase were prepared: A solution was prepared by mixing each complex with a commercially available laccase from Trametes versicolor, and the corresponding UV-vis and CD spectra were measured. 


\subsection{Measurements}

\subsubsection{Physical Measurements of $\mathbf{1}$ and $\mathbf{2}$}

IR spectra were recorded as $\mathrm{KBr}$ pellets on a FT-IR 4200 spectrophotometer (JASCO, Tokyo, Japan) in the range of $4000-400 \mathrm{~cm}^{-1}$ at $25^{\circ} \mathrm{C}$. Electronic (UV-vis) spectra were measured on a JASCO V-650 UV-vis spectrophotometer in the range of 800-200 nm at $25^{\circ} \mathrm{C}$. CD spectra were acquired on a JASCO J-820 spectropolarimeter in the same range and temperature. Preliminarily unit cells of single crystals were measured on an APEX2 CCD diffractometer (Bruker, Billerica, MA, USA) with Mo-K $\alpha$ radiation monochromated by graphite $(\lambda=0.71073 \AA)$.

\subsubsection{Electrochemical Measurements of $\mathbf{1}$ and $\mathbf{2}$}

Electrochemical measurements (cyclic voltammetry, CV) were carried out on a potentiostat (ALS 2323, BAS, Tokyo, Japan). A platinum spiral wire and an $\mathrm{Ag} / \mathrm{AgCl}$ electrode (saturated with $\mathrm{NaCl}$ ) were used as counter and reference electrodes, respectively, in the range of $-1.5 \mathrm{~V}$ to $+1.0 \mathrm{~V}$ vs. $\mathrm{Ag} / \mathrm{AgCl}$, using a complex $0.1 \mathrm{M}$ TBPA in DMSO solution as a supporting electrolyte, at a potential sweep rate of $50 \mathrm{mV} / \mathrm{s}$. The supporting electrolyte was prepared for 1 by dissolving $(0.01 \mathrm{mmol}, 5.1 \mathrm{mg})$ and TBPA $(0.3449 \mathrm{~g})$ in dehydrated DMSO to make up to $10 \mathrm{~mL}$, and for 2 by dissolving $(0.01 \mathrm{mmol}, 10.7 \mathrm{mg})$ and TBPA $(0.3504 \mathrm{~g})$ in dehydrated DMSO to make up to $10 \mathrm{~mL}$.

\subsubsection{Magnetic Measurements of $\mathbf{1}$ and $\mathbf{2}$}

The magnetic susceptibility was measured in a field of $10 \mathrm{kOe}$ and in the temperature range of 5-300 K, using a SQUID magnetometer (MPMS-XL7AC, Quantum Design, San Diego, CA, USA) on samples of complex 1: $0.0220 \mathrm{mmol}, 12.0 \mathrm{mg}$ and 2: $0.00125 \mathrm{mmol}$, 15.9 mg. Diamagnetic correction was carried out using Pascal constants [26].

\subsubsection{Electrochemical Measurements of $\mathbf{1}$ and $\mathbf{2}$ Docked into Laccase}

Electrochemical measurements (cyclic voltammetry, CV) were performed using RRDE electrodes for Nafion-coated laccase (commercially available enzyme from Trametes versicolor) and the complexes. The prepared films were fixed to the electrode by glutaraldehyde. Measurements were carried out on a potentiostat (ALS DY 2323). A platinum spiral wire and an $\mathrm{Ag} / \mathrm{AgCl}$ electrode (saturated with $\mathrm{NaCl}$ ) were used as counter and reference electrodes, respectively, in the range of $-1.5 \mathrm{~V}$ to $+1.0 \mathrm{~V} \mathrm{vs}$. $\mathrm{Ag} / \mathrm{AgCl}$, using phosphate buffered saline ( $0.01 \mathrm{M}, \mathrm{pH} 7.2$ to 7.4$)$ as the supporting electrolyte, at a potential sweep rate of $50 \mathrm{mV} / \mathrm{s}$.

\subsubsection{Magnetic Measurements of $\mathbf{1}$ and $\mathbf{2}$ Docked into Laccase}

Magnetic susceptibility was measured in a field of $50 \mathrm{kOe}$ and in the temperature range 5-300 K, using a SQUID magnetometer (Quantum Design MPMS-XL7AC). The samples were laccase, laccase reduced with a small amount of sodium dithionite under nitrogen, laccase complexed with $\mathbf{1}$, and laccase complexed with $\mathbf{2}$, using an established film forming method [27]. To create the film, 10\% PMMA acetone solution $(1 \mathrm{~mL})$ was spread on a glass plate and dried overnight. A solution $(1 \mathrm{~mL})$ of laccase $(48.6 \mathrm{mg})$ dissolved in phosphate buffer $(6 \mathrm{~mL})$ and a complex (1: $1.3 \mathrm{mg}$ and 2: $1.4 \mathrm{mg})$ in a phosphate buffer $(3 \mathrm{~mL})$ was mixed $(0.5 \mathrm{~mL})$, and spread thereon. The film was dried and hardened for approximately $2 \mathrm{~d}$, and was peeled off to make a sample. Unexpected technical error has occurred at $50 \mathrm{~K}$ for $\mathbf{1}$.

\subsubsection{Computational Methods}

The calculations of the optimized structure of the anionic complexes of $\mathbf{1}$ and $\mathbf{2}$ were carried out using the Gaussian 09W software package Revision D.02 (Gaussian, Inc., Wallingford, CT, USA) [28] in the Windows platform. All geometries were optimized by using B3LYP level of theory and basis set SDD. The frequency calculations were performed to optimize geometries using the identical level of theory and basis set. 
Molecular docking was carried out to estimate molecular interactions between the complexes anions (1: C1 and 2: C2) and amino acid residues of laccase using AutoDock 4.2.6 on a Windows platform equipped with 8 GB RAM and an Intel I5 processor [29]. The protein structure of laccase was retrieved from a protein data bank (PDB id: 1GYC). The A chain of laccase was modified by removing water and bound ligand. Missing amino acids were checked, and polar hydrogens were added to the protein structure. Center grid box $\mathrm{x}$ : 16.895, y: 21.372, z: 37.151, and number of points in $\mathrm{x}, \mathrm{y}, \mathrm{z}$ dimensions are considered as $30 \times 30 \times 30$ points, respectively, and grid spacing was taken as $0.3750 \AA$. AutoDock Tools modified the protein (laccase) and ligand (complexes anions of $\mathbf{1}$ and 2) structures. Ligands were prepared by adding Gasteiger charges, detecting roots, and choosing torsions from the torsion tree of the AutoDock Tools panel [30]. The docking procedure was performed by using the Lamarckian genetic algorithm [31].

\section{Results and Discussion}

We confirmed the similarity of prepared and reported samples using the IR spectra recorded for $\mathbf{1}$ and $\mathbf{2}$ and also preliminary measurements of unit cells by X-ray crystallography for $\mathbf{1}$. As detailed in Table 1, the infrared absorption spectrum of the ion pair of 1 (Figure 2a) shows absorption bands that are consistent with the previously reported data [32] obtained from collected and milled single crystals, which gives an insight about the purity of the sample.

Table 1. Proposed assignments of the absorption bands of the two ion pairs of $\mathbf{1}$ and $\mathbf{2}$ (wavenumbers, $\left.\mathrm{cm}^{-1}\right)$.

\begin{tabular}{cccc}
\hline Ion Pair of $\mathbf{1}$ & $\begin{array}{c}\text { Ion Pair of 1 [32] } \\
\text { (as Previously Reported) }\end{array}$ & Ion Pair of $\mathbf{2}$ & Attribution \\
\hline 3459,2941 & $3482,3373,2935$ & 3336,2919 & $v(\mathrm{C}-\mathrm{H}) ; v(\mathrm{~N}-\mathrm{H})$ \\
3162,3102 & 3229,3082 & 3196 & $v_{\mathrm{s}}(\mathrm{O}-\mathrm{H}) ; v_{\mathrm{as}}(\mathrm{O}-\mathrm{H})$ \\
- & - & 2363 & $v(\mathrm{~N}-\mathrm{H} \ldots \mathrm{O})$ \\
1644 & 1639 & 1654 & $v_{\mathrm{as}}(\mathrm{COO})$ \\
1561 & 1559 & - & $v(\mathrm{C}=\mathrm{C})$ \\
1382 & 1397 & 1398 & $v_{\mathrm{s}}(\mathrm{COO})$ \\
- & - & 1297 & $v\left(\mathrm{C}-\mathrm{NH} \mathrm{H}_{2}\right)$ \\
1253,1212 & 1236,1212 & 1170,1121 & $\gamma(\mathrm{C}-\mathrm{N})$ \\
1068 & 1061 & - & $\delta(\mathrm{O}-\mathrm{H})$ \\
994 & 951 & 964 & $\gamma(\mathrm{V}=\mathrm{O})$ \\
891 & 891 & - & $\delta(\mathrm{N}-\mathrm{H})$ \\
808 & 802 & 800 & $\gamma(\mathrm{C}-\mathrm{N}) ; \gamma(\mathrm{C}-\mathrm{C})$ \\
552,479 & 530,478 & 537 & $v(\mathrm{~V}-\mathrm{O})$ \\
\hline
\end{tabular}

Based on these attributions, the infrared absorption spectrum the ion pair of 2 (Figure $2 b$ ) shows similar characteristic vibrations of the heterocyclic aromatic ring. In the high frequencies domain, the bands at 3336 and $2919 \mathrm{~cm}^{-1}$ are due to the stretching vibration frequencies of the $\mathrm{N}-\mathrm{H}$ and $\mathrm{C}-\mathrm{H}$ bonds. Absorption bands at 1170, 1121 and $800 \mathrm{~cm}^{-1}$ may be attributed to $\gamma(\mathrm{C}-\mathrm{N}), \gamma(\mathrm{C}-\mathrm{N})$ and $\gamma(\mathrm{C}-\mathrm{C})$, respectively. Both absorption spectra also exhibit the similar characteristic features of the oxalate anion. For the ion pair of 2, the strong band at $1654 \mathrm{~cm}^{-1}$ can be assigned to the asymmetric vibration of the oxalate $v_{\text {as }}(\mathrm{COO})$ while the peak at $1398 \mathrm{~cm}^{-1}$ can be attributed to symmetric vibrations $v_{\mathrm{s}}(\mathrm{COO})$. The vanadyl stretching mode $v(\mathrm{~V}=\mathrm{O})$ can be observed at around $964 \mathrm{~cm}^{-1}$ and the absorption bands at around $537 \mathrm{~cm}^{-1}$ are attributable to of $\mathrm{V}-\mathrm{O}$ (oxalate) stretching vibration confirming the coordination of the metal center. The presence of water molecules may be deduced from the band at $3196 \mathrm{~cm}^{-1}$ and the large band at around $3500 \mathrm{~cm}^{-1}$ attributed to the asymmetric and symmetric vibrations of the $\mathrm{O}-\mathrm{H}$ bonds.

Distinct from the ion pair of $\mathbf{1}$, the infrared absorption spectrum of the ion pair of $\mathbf{2}$ shows a band at around $1297 \mathrm{~cm}^{-1}$ that may be attributed to the stretching modes of the C-NH $\mathrm{N}_{2}$ bonds [33] and a band at $2363 \mathrm{~cm}^{-1}$ attributed to $v(\mathrm{~N}-\mathrm{H} . . . \mathrm{O})$. 


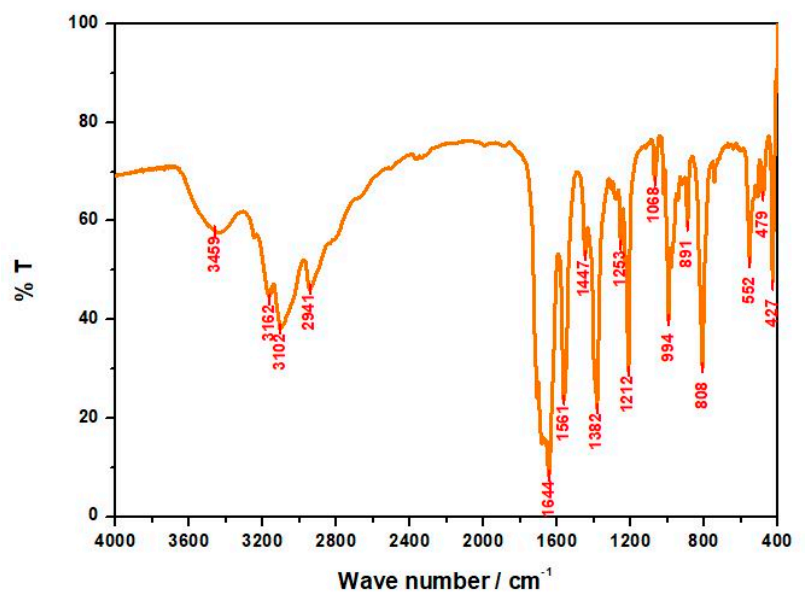

(a)

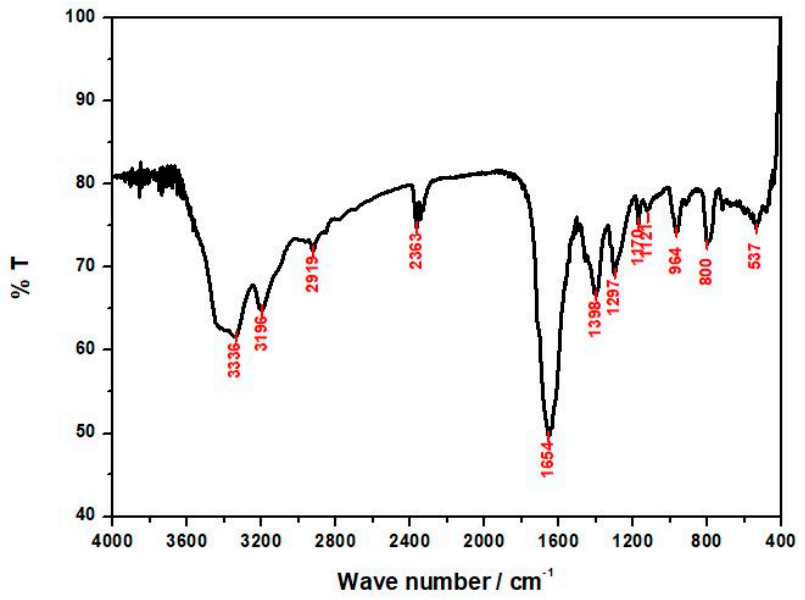

(b)

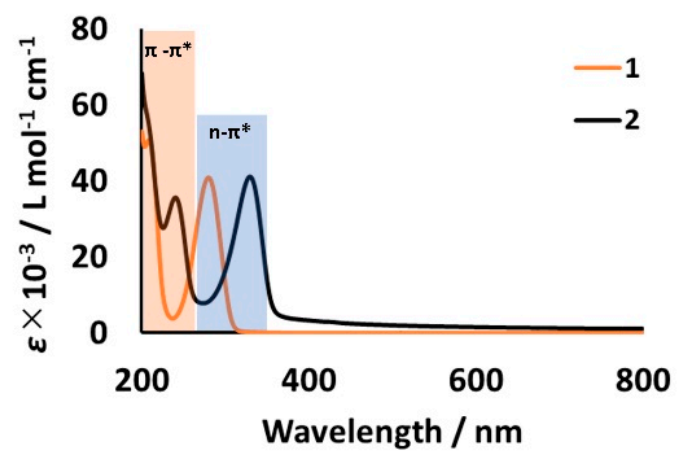

(c)

Figure 2. I.R. of complex $\mathbf{1}$ (a) and complex $\mathbf{2}(\mathbf{b})$ and UV-vis (c) spectra of complex $\mathbf{1}\left(1.56 \times 10^{-5} \mathrm{M}\right.$, orange $)$ and complex $2\left(5.52 \times 10^{-6} \mathrm{M}\right.$, black $)$.

In the UV-vis absorption spectra of the ion pairs of $\mathbf{1}$ and $\mathbf{2}$ (Figure 2c), an electron transition ( $\mathrm{n}-\pi^{*}$ transition), including the organic cations, from the $\mathrm{n}$ orbital of the lone pair to the empty $\pi^{*}$ orbital at the carbonyl group $(\mathrm{C}=\mathrm{O})$ was observed at around $300 \mathrm{~nm}$. The fact that the $n-\pi^{*}$ transition of $\mathbf{1}$ compared to $\mathbf{2}$ is seen on the short wavelength side can be understood by looking at the crystal structures [24]. Different from crystalline samples in the solid state served for X-ray crystallography in the previous study, these complexes were in equilibrium or mixtures of two V ion valence states. Moreover, DFT simulated UV-vis spectra were in general "qualitatively" in agreement with experimental ones. However, qualitative assignments of bands can be done with DFT simulated UV-vis spectra. In this case, they are apparently different. As depicted in Figure 3a, hydrogens of the protonated nitrogen atoms (Donor: D) of the 4-(dimethylamino)pyridinium cations in the structure of complex 1 are engaged in hydrogen bonds with the oxygen atoms (Acceptor: A) of the carbonyl groups of the oxalate ligand in the anionic complex with $\mathrm{D}$... A distances of 2.777(3) and 3.002(3) $\AA$ [24]. Accordingly, in Figure 3b, hydrogens of the nitrogen atoms (D) of the 2,6-diaminopyridinium cations in the structure of $\mathbf{2}$ are engaged in hydrogen bonds with the oxygen atoms (A) of the carbonyl groups of the oxalate ligand in the anionic complex, with D ... A distances ranging from 2.831(1) to 3.315(1) $\AA$ [25]. Since complex $\mathbf{1}$ is considered to have stronger intermolecular hydrogen bonds (shorter D ... A distances), the lone pair on the oxygen atom in $\mathbf{1}$ is more stable, and the $\mathrm{n}-\pi^{*}$ transition would not occur unless short-wavelength light was applied. At approximately $200 \mathrm{~nm}$, an electronic transition ( $\pi-\pi^{*}$ transition) from HOMO to LUMO at the carbonyl group $(\mathrm{C}=\mathrm{O})$ was observed at a shorter wavelength side for $\mathbf{1}$ compared to $\mathbf{2}$, ascribed to the same 
structural reasons. By examining the spectrum of 2 , it can be seen that the peak of the $\pi-\pi^{*}$ transition is split into two. This may be attributable to the multiple transitions from HOMO-1 to LUMO and from HOMO to LUMO+1 that occur when the applied wavelength is slightly altered.

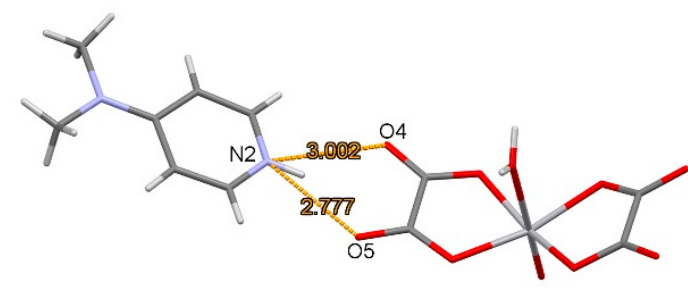

(a)

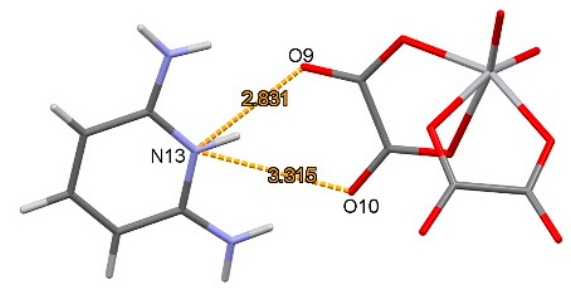

(b)

Figure 3. The D ... A distances (orange dashed lines) separating the protonated nitrogen atom of the 4-(dimethylamino)pyridinium cation in the structure of complex $\mathbf{1}$ (a) and the 2,6-diaminopyridinium cation in the structure of complex 2 (b) from the corresponding oxygen atoms in the carbonyl group of the oxalate ligand.

CD spectra of complexes 1 and 2 exhibited no peaks due to chirality, in full agreement with the structural data $[24,25]$, confirming that both complexes have no optical isomers.

Figures 4 and 5 show the structures optimized by TD-DFT and their spectra. The UVvis spectra are thought to be related to electron transfer from HOMO to LUMO (transition from ligand to metal, i.e., LMCT). In fact, the pentavalent $\mathrm{d}^{0}$ anionic complex of $\mathbf{2}$ exhibits an intense transition which ranges from $320-420 \mathrm{~nm}$, assigned to LMCT excitation of the type $\mathrm{O}$ (oxalate) $\rightarrow \mathrm{V}^{5+}$. LMCT can be regarded as an internal redox transition, with the metal being reduced and the ligand being oxidized. It is therefore possible to correlate LMCT energy with the redox properties of metal and ligand. CD spectra were also calculated in connection with the laccase docking experiment.
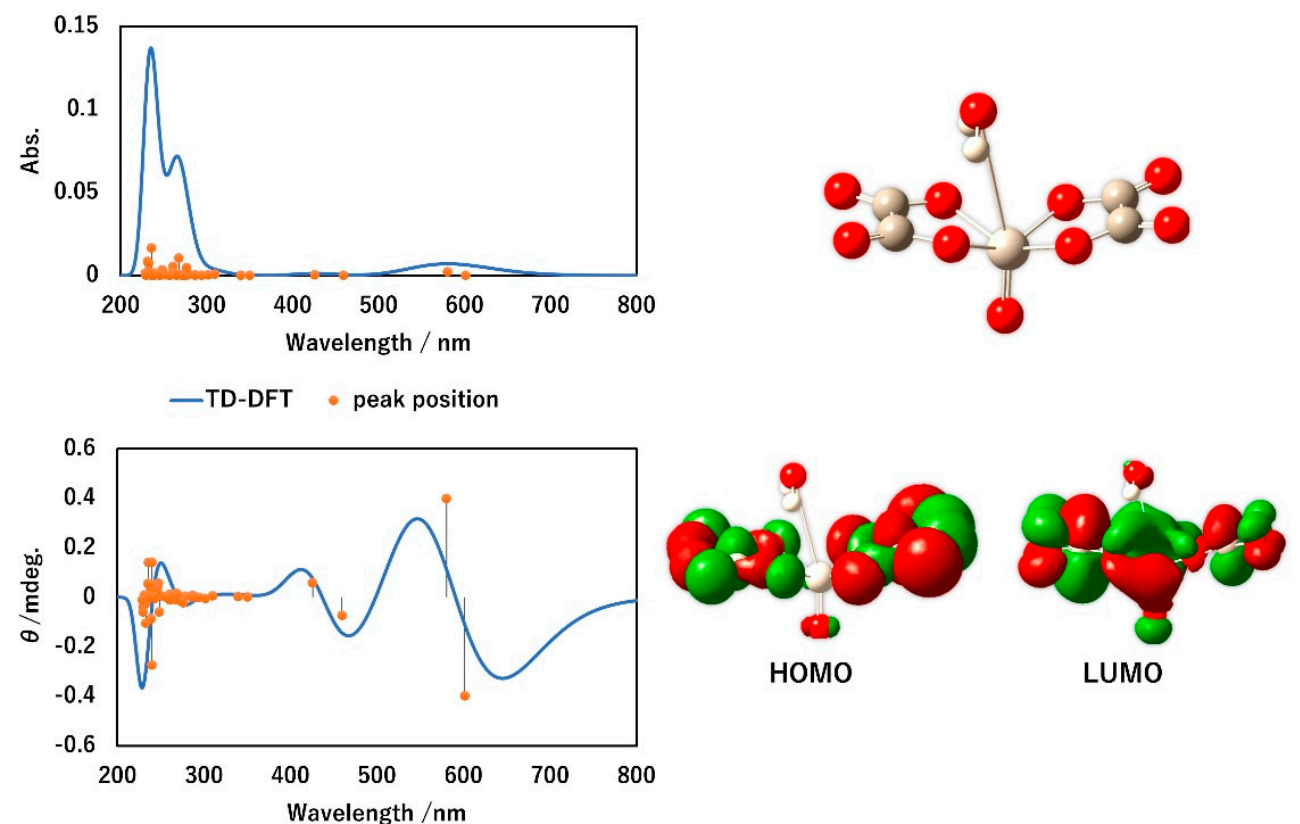

Figure 4. Calculated UV-vis (upper left), CD (lower left) spectra, and structural optimization diagram (right) of the oxovanadium moiety in complex $\mathbf{1}$. 

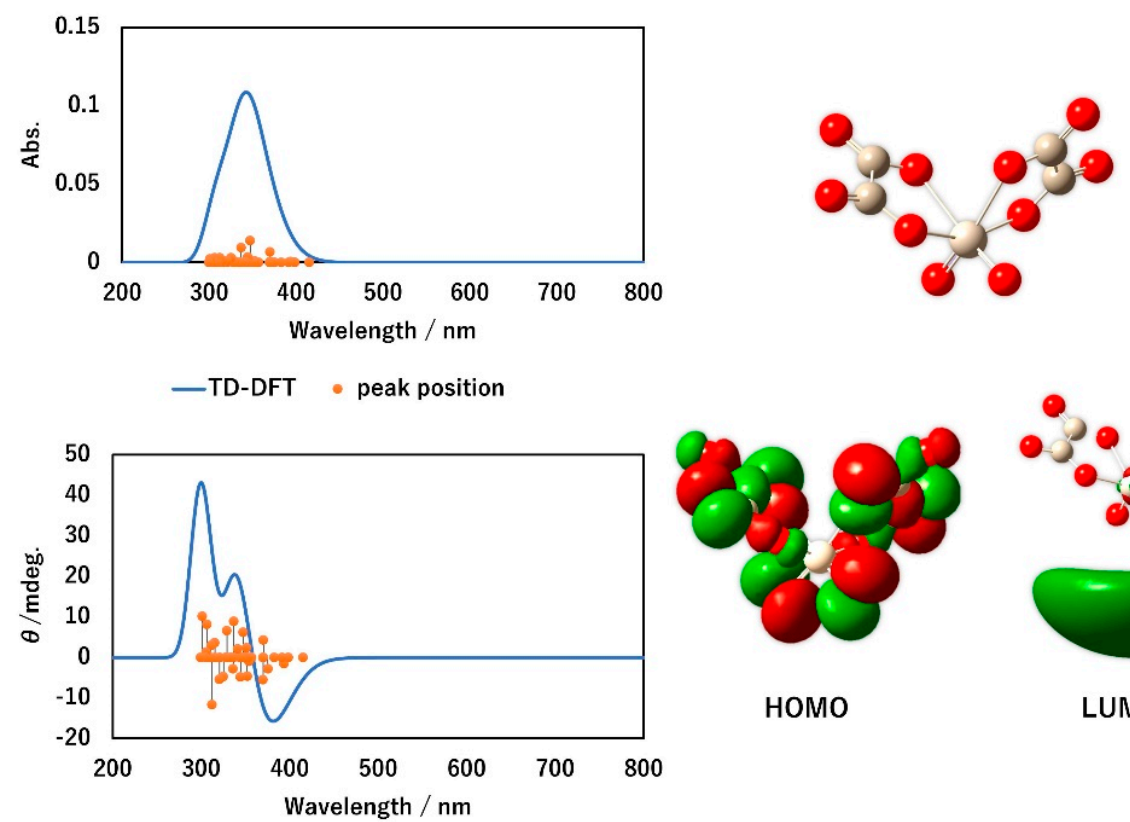

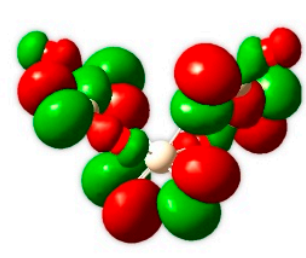

HOMO

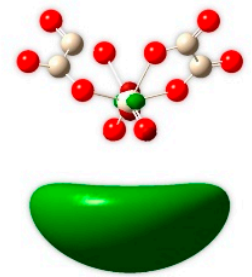

LUMO

Figure 5. Calculated UV-vis (upper left), CD (lower left) spectra, and structural optimization diagram (right) of the oxovanadium moiety in complex 2.

In the ESR spectra of $\mathbf{1}$ and $\mathbf{2}$ (Figure 6a), the calculated Landé factors (g) were 2.01 and 1.97 , respectively. In previous reports [24,25], the vanadium ion was verified to have an oxidation state of +4 for $\mathbf{1}$ and +5 for $\mathbf{2}$, using bond-valence sum calculations [34] based on single-crystal structures [24,25]. Broad and split ESR spectra and large deviation of effective magnetic moment of calculated spin angular momentum suggested the presence of the different valence of $\mathrm{V}(\mathrm{IV})$ and $\mathrm{V}(\mathrm{V})$. Although there should be no paramagnetism in $\mathbf{2}$, some unpaired electrons were unexpectedly found in the d orbitals. We thought that complex 2 was generated in an environment that easily touches air, and that the valence changed due to the heating operation to blow off the solvent after and before the generation. Indeed, this constitutes an advantage for the redox function of the $\mathrm{V}=\mathrm{O}$ moiety and emphasizes the fact that the +5 oxidation state easily switches under aerobic conditions.

The magnetic moment $\left(\mu_{\mathrm{s}}\right)$ expected value, calculated from the spin-only formula, is $\mu_{\mathrm{s}}=1.73$ for $\mathrm{V}^{4+}$ with one unpaired electron $\left(\mathrm{d}^{1}, \mathrm{~S}=1 / 2\right)$ and $\mu_{\mathrm{s}}=0$ for $\mathrm{V}^{5+}$ with zero unpaired electrons $\left(\mathrm{d}^{0}, \mathrm{~S}=0\right)$. From the magnetic susceptibility results of $\mathbf{1}$ and 2 (Figure $6 \mathrm{~b})$, the effective magnetic moment $\left(\mu_{\text {eff }}\right)$ was calculated to be 1.02 and 1.64 B.M., respectively, at $300 \mathrm{~K}$. Since both 1 and 2 take values between 0 and 1.73, the measurement confirms the ESR results, that the valence of vanadium is easily changed and that both samples of 1 and 2 have different valences of $V(I V)$ and $V(V)$, which provides insight into the electrochemical behavior of the complexes.

Based on this, CV measurement was performed with dehydrated DMSO as a solvent. As depicted in Figure 6c, both 1 and 2 caused multiple valence changes. Complex $\mathbf{2}$ shows peaks that cannot be assigned. When measuring in step 2, the peak may be resultant from metal ions that were accidentally included in the ultrapure water used for cleaning. Based on many previous papers and our studies, redox peaks of the highest positive potential can be assigned as reduction of oxygen by laccase, and peaks of the lower negative potential can be assigned as $\mathrm{V}(\mathrm{V} / \mathrm{IV})$ of $\mathbf{1}$ or $\mathbf{2}$. The additional peaks should be assigned intermediate states of laccase, which could not be confirmed clearly. 


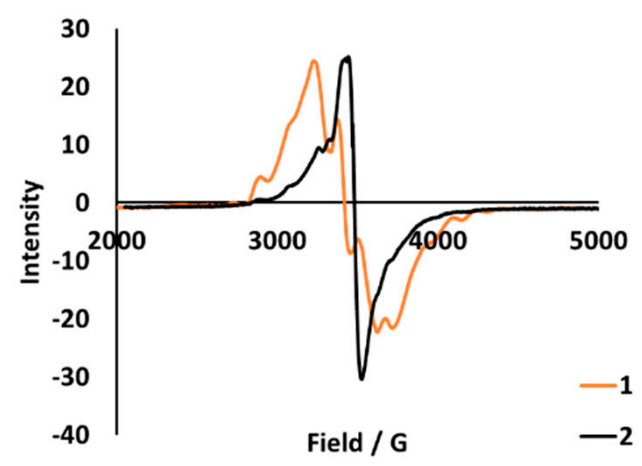

(a)

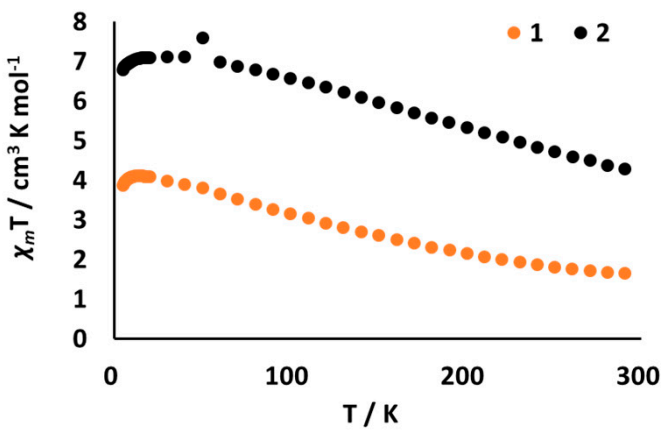

(b)

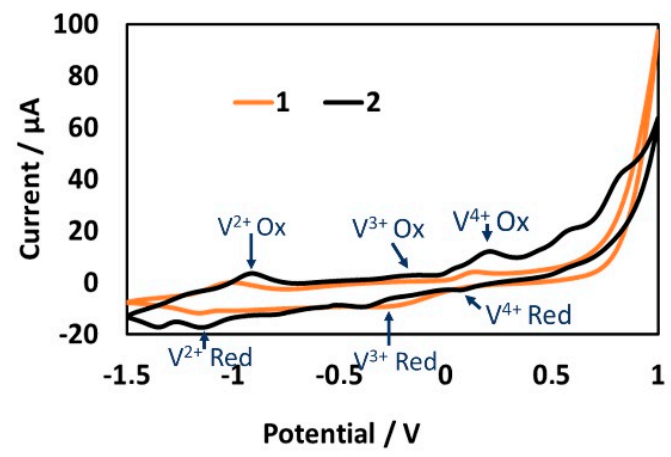

(c)

Figure 6. ESR spectra (a), $\chi_{m} \mathrm{~T}$ vs. T plot (b) and cyclic voltammograms (c) of complex $\mathbf{1}$ (orange) and complex 2 (black).

Figure 7 presents the docking evaluation results. The UV-vis spectrum of laccase (Figure 7a) does not exhibit significant absorptions. During the reaction of $\mathrm{Cu}(\mathrm{II} / \mathrm{I})$ in laccase, the intensity of charge transfer bands may be weakened besides the problem of concentration. When the complex + laccase's hybrid materials are formed, a new absorption band due to electron transfer was developed, so the possibility of chemisorption can be asserted. Furthermore, when the same samples used for recording UV-vis spectra were subjected to $C D$ measurement, a peak not observed in laccase was expressed in the complex. The UV-vis and CD spectral change of $\mathbf{1}$ may also due to aggregation of laccase by addition of 1 (Figure $7 \mathrm{a}, \mathrm{b}$ ). The CD spectrum (Figure $7 \mathrm{~b}$ ) confirms the presence of protein secondary structures, such as $\alpha$-helix and $\beta$-sheet. Both spectral features suggested that a hybrid material (anionic complex + laccase) is formed by chemisorption of the complex at a certain surface region of laccase.

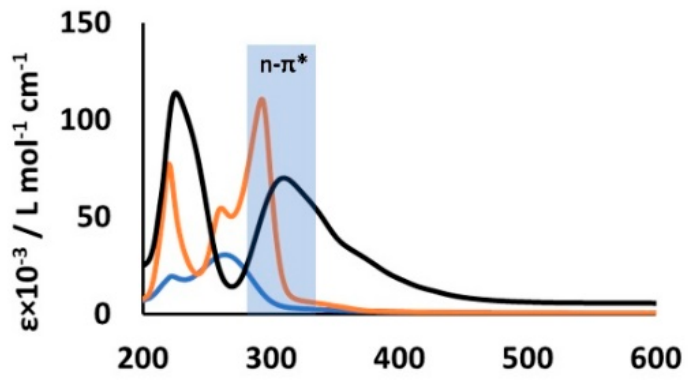

(a)

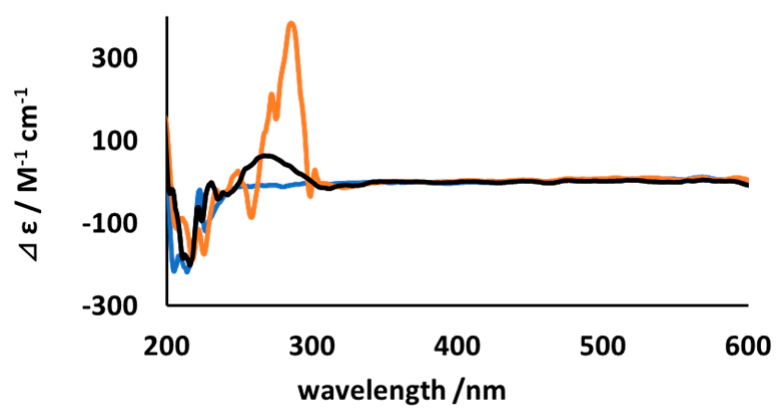

(b)

Figure 7. UV-vis (a), CD (b) spectra of laccase $\left(2.17 \times 10^{-5} \mathrm{M}\right.$, blue), anionic complex of $\mathbf{1}\left(5.52 \times 10^{-5} \mathrm{M}\right)+$ laccase $\left(2.14 \times 10^{-5} \mathrm{M}\right)$ (orange), and anionic complex of $2\left(5.52 \times 10^{-5} \mathrm{M}\right)+$ laccase $\left(2.27 \times 10^{-5} \mathrm{M}\right)(\mathrm{black})$. 
Figure 8 shows the CV measurement results of anionic complexes of $\mathbf{1}$ and $\mathbf{2}$ when docked into laccase. The oxygen reduction reaction's current value was larger in the anionic complex + laccase than in laccase alone. Although the precise mechanism is unknown, it can be concluded that the docking of the anionic complexes increased the rate of the oxygen reduction reaction. In addition, the potential peak of the oxygen reduction reaction approaches 0 due to the docking of the complexes. The oxygen reduction reaction proceeds in lower potentials when catalyzed by anionic complex + laccase than when catalyzed by laccase, which shows that the laccase's catalytic performance was improved by the anionic complex of 2.

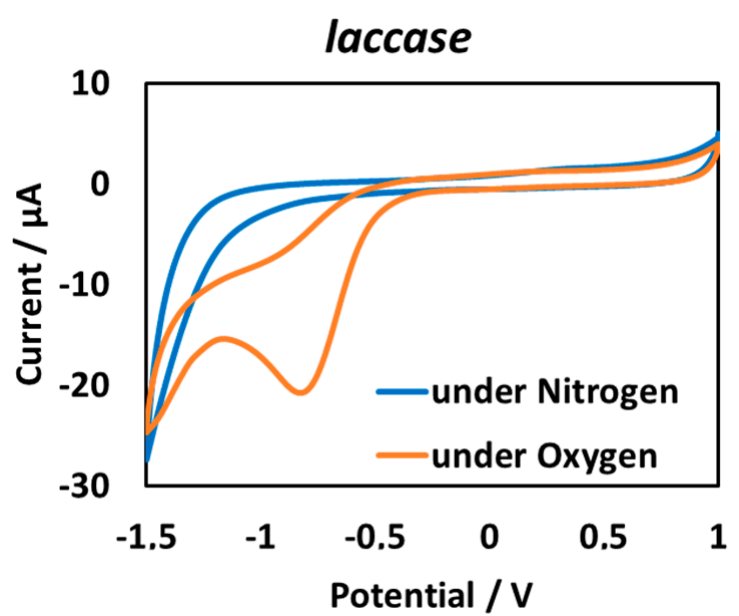

(a)

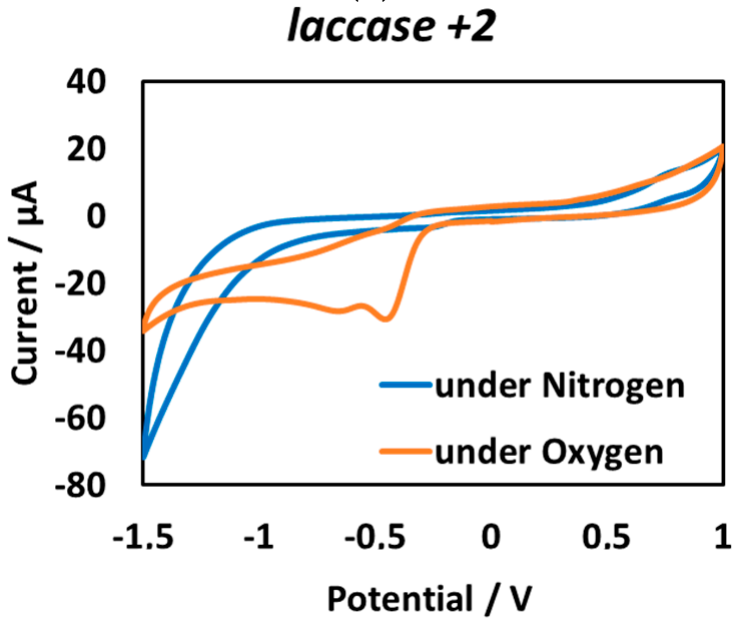

(c)

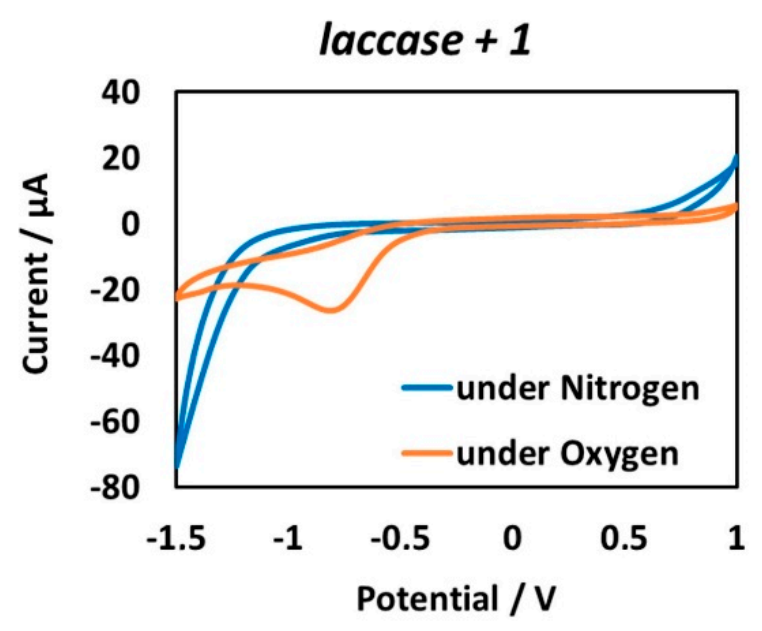

(b)

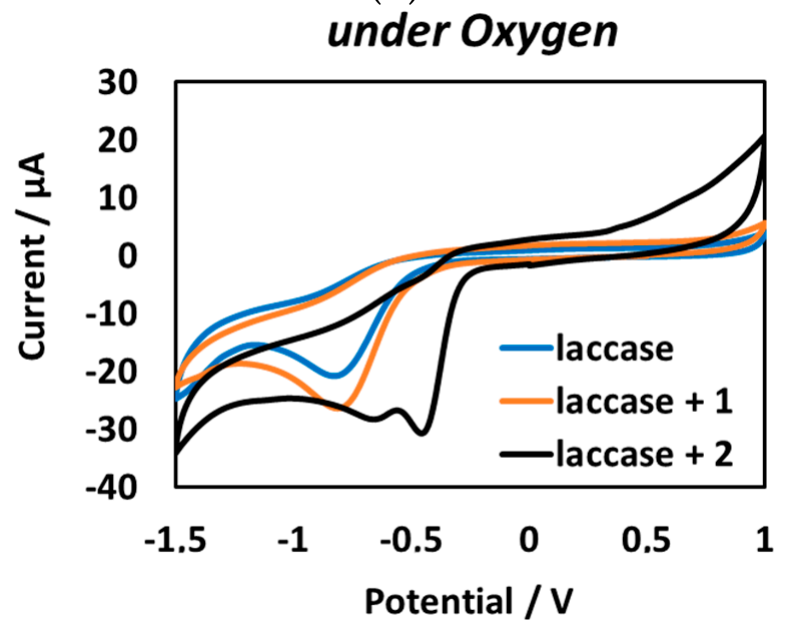

(d)

Figure 8. Cyclic voltammograms when the membrane docked with laccase is attached to the working electrode. (a) laccase, (b) laccase $+\mathbf{1}$, (c) laccase $+\mathbf{2}$ and (d) under Oxygen.

Figure 9 presents the magnetic susceptibility results of the hybrid materials of PMMA + anionic complexes of $\mathbf{1}$ and $\mathbf{2}$ when docked in laccase. It is assumed that the PMMA membrane responds in the opposite direction due to diamagnetism. The reduced laccase membrane's value was subtracted from the value of the laccase or the composite membrane (laccase + anionic complex), and the obtained plot result was corrected with the reversed sign.

The value of the magnetic susceptibility was negative. Presumed to have responded in the opposite direction due to the diamagnetism of the PMMA membrane, the value of the reduced laccase membrane was subtracted from the value of the laccase or the hybrid film of the laccase and the complex (1 or $\mathbf{2})$, and the result was plotted with the sign reversed. 


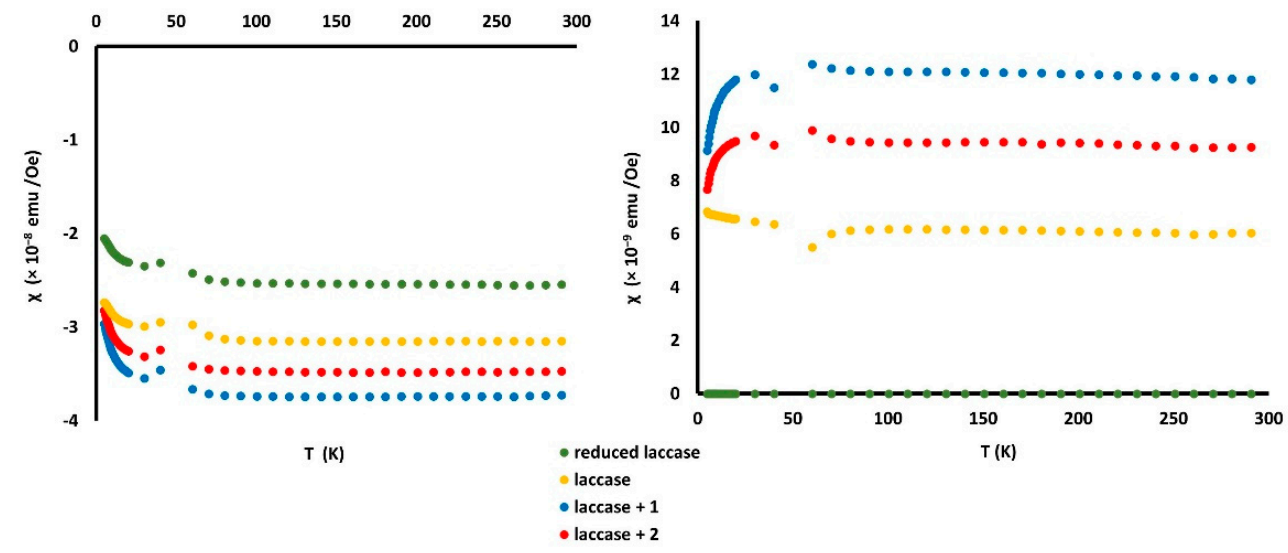

Figure 9. Magnetic susceptibility $\chi(\mathrm{emu} / \mathrm{Oe})$ vs. T (K) plot (left), corrected plot (right).

For laccase alone, at $300 \mathrm{~K}$, the magnetic moment $\left(\mu_{\text {eff }}\right)$ per molecule is 3.05 B.M., which is in good agreement with the expected value of $3.00 \mathrm{for}$ two $\mathrm{Cu}^{2+}$, as the theoretical effective magnetic moment is slightly larger than the value for two free electrons of 2.83 B.M. [35]. Therefore, the obtained magnetic moment for the oxovanadium complexes of 1 and 2 docked into laccase are 0.95 and 0.49 , respectively.

For the oxovanadium complex of $\mathbf{1}$, the magnetic moment when docked into laccase has not changed (calculated for 1 alone, 1.02 B.M.), and the anionic complex remained without significant electron transfer with the laccase. For the oxovanadium complex of 2 , a larger amount of electron transfer with laccase is presumed. Compared to the calculated value of 1.64, the anionic complex was subjected to an oxidation that raised its valence in the presence of laccase and under the magnetic field.

In the computational docking simulation, the best-fit ligand conformations were selected based on their minimum binding energies. Among the two anionic complexes, the anionic complex of $\mathbf{2}(\mathrm{C} 2)$ (Figure 10) showed the highest docking score, i.e., $-8.6 \mathrm{kcal} / \mathrm{mol}$ $(-7.4 \mathrm{kcal} / \mathrm{mol}$ for $\mathbf{1}(\mathrm{C} 1))$. It formed some bonds with laccase, and they are depicted in Table 2. The highest docking score agrees with the excellent docking with laccase supported by $\mathrm{CV}$ results. These findings can be further utilized in developing less expensive mediators that can be applied in growing biofuel and bioremediation industries.

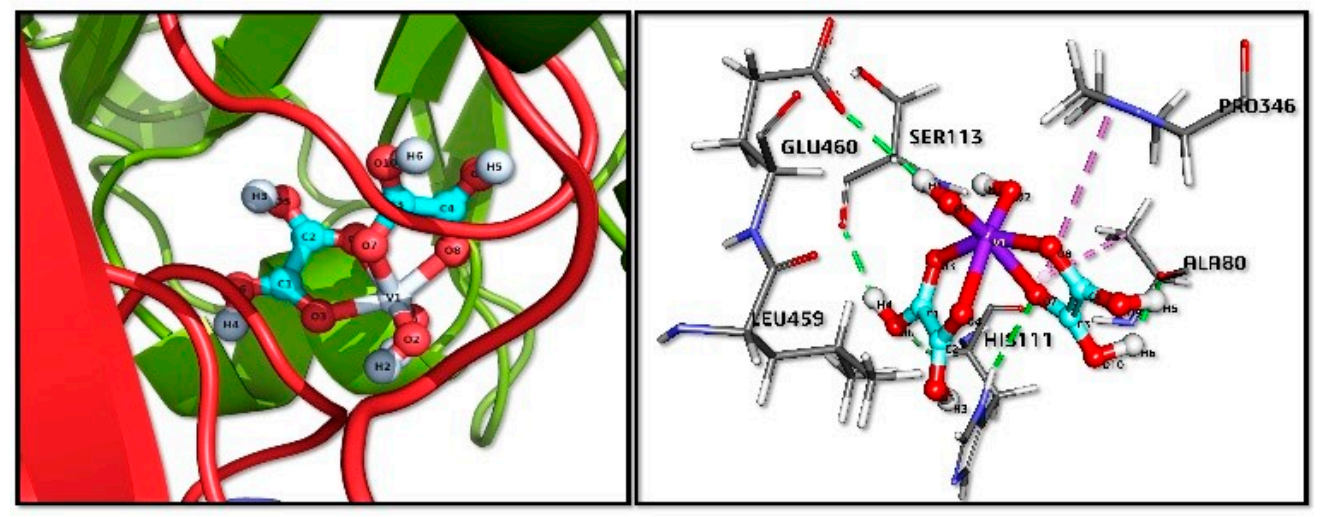

Figure 10. Comprehensive perception of laccase (receptor) and C2 (ligand) interaction after docking. $\mathrm{C} 2$ was docked in the active site of the laccase receptor. The ribbon model represents the laccase receptor's secondary structure, and C2 is represented by the ball and stick model (left). Interactions of ligand with laccase receptor amino acids omitting laccase receptor, with ligand surrounding amino acids in three-letter-code represented in dark blue (right). 
Table 2. Bond distances and type between laccase receptor and C2.

\begin{tabular}{|c|c|c|c|}
\hline Bond Name & Distance (§̊) & Bond Category & Bond Type \\
\hline C2:H6-A:ALA80:O & 1.94933 & Hydrogen bond & $\begin{array}{l}\text { Conventional } \\
\text { hydrogen bond }\end{array}$ \\
\hline C2:H5-A:ALA80:O & 1.98495 & Hydrogen bond & $\begin{array}{l}\text { Conventional } \\
\text { hydrogen bond }\end{array}$ \\
\hline C2:H4-A:SER113:O & 2.14896 & Hydrogen bond & $\begin{array}{l}\text { Conventional } \\
\text { hydrogen bond }\end{array}$ \\
\hline A:HIS111:HD1-C2:O7 & 2.65241 & Hydrogen bond & $\begin{array}{l}\text { Conventional } \\
\text { hydrogen bond }\end{array}$ \\
\hline C2:H1-A:GLU460:OE1 & 2.65976 & Hydrogen bond & $\begin{array}{l}\text { Conventional } \\
\text { hydrogen bond }\end{array}$ \\
\hline A:HIS111:HA-C2:O6 & 2.74924 & Hydrogen bond & $\begin{array}{c}\text { Carbon } \\
\text { hydrogen bond }\end{array}$ \\
\hline A:ALA80-C2 & 4.35591 & Hydrophobic & Pi-Alkyl \\
\hline A:PRO346-C2 & 5.29772 & Hydrophobic & Pi-Alkyl \\
\hline
\end{tabular}

Over the past 10 years approximately, the number of studies describing the development of enzymatic biofuel cells has continued to increase. However, to the best of our knowledge, the literature lacks reports of investigations evaluating redox-active vanadium compounds for mediated electron transfer in BFCs. This fact persists despite the large variety of vanadium complexes of different oxidation states, ligand structure, coordination geometry, and their frequent use as catalysts.

As a consequence, we took inspiration from previously reported work for other metal complexes, and newly proved how $\mathrm{V}=\mathrm{O}$ complex 2 may act as an electron relay to transfer electrons from laccase's active site to the electrode surface. The mechanisms underlying this behavior are shown to be its bonding to the enzyme, demonstrated by the highest docking score, and the modifications revealed in the UV-vis and CD spectra of the anionic complex + laccase's hybrid materials.

\section{Conclusions}

By evaluating the physical properties of oxovanadium complexes $\mathbf{1}$ and $\mathbf{2}$ and examining the electrochemical and computational behaviors of hybrid compounds (anionic complex + laccase), it was proven that the anionic complex of $\mathbf{2}+$ laccase has the best docking score $(-8.6 \mathrm{kcal} / \mathrm{mol})$, the lowest reduction potentials, and the highest current density. Therefore, $\mathrm{V}=\mathrm{O}$ anionic complex of 2 promoted the reduction reaction of oxygen to water, rather than the laccase alone and anionic complex of $\mathbf{1}+$ laccase, and may be suitable as a metal complex mediator to improve electron transfer efficiency between the electrode and laccase in biofuel cells.

Author Contributions: N.K. performed most part of the laboratory and instrumental work. Specifically, the preparation and characterization of the compounds $\mathbf{1}$ and $\mathbf{2}$ and the hybrid materials when docked into laccase. Writing — Original draft preparation and figures preparation; H.S. WritingReview and editing, Figures preparation and Submission; S.P. Writing-Review and editing, Figures preparation and Docking simulation; S.K. DFT calculations; T.H. Checking manuscript; T.A. Supervision and coordination of the experimental work with the computational results, as well as the correction and revision of this manuscript. All authors have read and agreed to the published version of the manuscript.

Funding: This research received no external funding.

Data Availability Statement: The data presented in this study are openly available in the article.

Conflicts of Interest: The authors declare no conflict of interest to publish the results. 


\section{References}

1. Le Goff, A.; Holzinger, M.; Cosnier, S. Recent progress in oxygen-reducing laccase biocathodes for enzymatic biofuel cells. Cell. Mol. Life Sci. 2015, 72, 941-952. [CrossRef] [PubMed]

2. Cooney, M.J.; Svoboda, V.; Lau, C.; Martin, G.; Minteer, S.D. Enzyme catalysed biofuel cells. Energy Environ. Sci. 2008, 1, 320-337. [CrossRef]

3. Elouarzaki, K.; Cheng, D.; Fisher, A.C.; Lee, J.M. Coupling orientation and mediation strategies for efficient electron transfer in hybrid biofuel cells. Nat. Energy 2018, 3, 574-581. [CrossRef]

4. Sakai, H.; Nakagawa, T.; Tokita, Y.; Hatazawa, T.; Ikeda, T.; Tsujimura, S.; Kano, K. A high-power glucose/oxygen biofuel cell operating under quiescent conditions. Energy Environ. Sci. 2009, 2, 133-138. [CrossRef]

5. Ivanov, I.; Vidaković-Koch, T.; Sundmacher, K. Recent Advances in Enzymatic Fuel Cells: Experiments and Modeling. Energies 2010, 3, 803-846. [CrossRef]

6. Solomon, E.I.; Szilagyi, R.K.; DeBeer George, S.; Basumallick, L. Electronic Structures of Metal Sites in Proteins and Models: Contributions to Function in Blue Copper Proteins. Chem. Rev. 2004, 104, 419-458. [CrossRef] [PubMed]

7. Jones, S.M.; Solomon, E.I. Electron transfer and reaction mechanism of laccases. Cell. Mol. Life Sci. 2015, 72, 869-883. [CrossRef]

8. Prasad, K.P.; Chen, Y.; Chen, P. Three-Dimensional Graphene-Carbon Nanotube Hybrid for High-Performance Enzymatic Biofuel Cells. ACS Appl. Mater. Interfaces 2014, 6, 3387-3393. [CrossRef] [PubMed]

9. Moehlenbrock, M.J.; Minteer, S.D. Extended lifetime biofuel cells. Chem. Soc. Rev. 2008, 37, 1188-1196. [CrossRef]

10. Neto, S.A.; Forti, J.C.; Andrade, A.R. De An Overview of Enzymatic Biofuel Cells. Electrocatalysis 2010, 1, 87-94. [CrossRef]

11. Takeuchi, Y.; Sunaga, N.; Akitsu, T. Anthraquinone and L-amino Acid Derivatives Schiff Base Cu(II) Complexes as a Mediator between Cathode of Biofuel Cell and Oxygen-reducing Laccase Abstract. Trends Green Chem. 2017, 3, 1-8. [CrossRef]

12. Patra, S.; Chatterjee, S.; Si, T.K.; Mukherjea, K.K. Synthesis, structural characterization, VHPO mimicking peroxidative bromination and DNA nuclease activity of oxovanadium(v) complexes. Dalton Trans. 2013, 42, 13425-13435. [CrossRef]

13. Ando, R.; Mori, S.; Hayashi, M.; Yagyu, T.; Maeda, M. Structural characterization of pentadentate salen-type Schiff-base complexes of oxovanadium (IV) and their use in sulfide oxidation. Inorg. Chim. Acta 2004, 357, 1177-1184. [CrossRef]

14. Maeda, Y.; Kakiuchi, N.; Matsumura, S.; Nishimura, T.; Kawamura, T.; Uemura, S. Oxovanadium complex-catalyzed aerobic oxidation of propargylic alcohols. J. Org. Chem. 2002, 67, 6718-6724. [CrossRef]

15. Shen, Y.; Atobe, M.; Li, W.; Nonaka, T. Paired electrosynthesis of epoxides and dibromides from olefinic compounds. Electrochim. Acta 2003, 48, 1041-1046. [CrossRef]

16. Sakurai, H.; Tsuchiya, K. A biomimetic model for vanadium-containing bromoperoxidase. FEBS Lett. 1990, $260,109-112$. [CrossRef]

17. Butler, A.; Carrano, C.J. Coordination chemistry of vanadium in biological systems. Coord. Chem. Rev. 1991, 109, 61-105. [CrossRef]

18. da Silva, J.A.L.; da Silva, J.J.R.F.; Pombeiro, A.J.L. Oxovanadium complexes in catalytic oxidations. Coord. Chem. Rev. 2011, 255, 2232-2248. [CrossRef]

19. Takeuchi, Y.; Akitsu, T. Anthraquinone Derivative Chiral Schiff Base Copper(II) Complexes for Enzyme Type Bio-Fuel Cell Mediators. J. Electr. Eng. 2016, 4, 189-195. [CrossRef]

20. Mitsumoto, Y.; Sunaga, N.; Akitsu, T. Polarized light induced molecular orientation in laccase for chiral azo- salen Mn(II), Co(II), $\mathrm{Ni}(\mathrm{II}), \mathrm{Cu}(\mathrm{II}), \mathrm{Zn}(\mathrm{II})$ mediators toward application for biofuel cell. Scifed J. Chem. Res. 2017, 1, 1-12.

21. Sano, A.; Yagi, S.; Haraguchi, T.; Akitsu, T. Synthesis of MnII and CuII complexes including azobenzene and its application to mediators of laccase for biofuel cells. J. Indian Chem. Soc. 2018, 95, 487-494.

22. Kunitake, F.; Kim, J.; Yagi, S.; Yamzaki, S.; Haraguchi, T.; Akitsu, T. Chiral Recognition of Azo-Schi ff Base Ligands, Their Cu(II) Complexes, and Their Docking to Laccase as Mediators. Symmetry 2019, 11, 666. [CrossRef]

23. Kajiwara, K.; Yamane, S.; Haraguchi, T.; Pradhan, S.; Sinha, C.; Giri, S.; Roymahaptra, G.; Moon, D.; Akitsu, T. Computational Design of Azo-anthraquinone Schiff Base Mn Complexes as Mediators for Biofuel Cell Cathode. J. Chem. Chem. Eng. 2019, 13, 23-33. [CrossRef]

24. Sehimi, H.; Chérif, I.; Zid, M.F. Crystal structure of bis[4-(dimethylamino)-pyridinium] aquabis(oxalato)oxidovanadate(IV)dihydrate. Acta Crystallogr. Sect. E 2016, 72, 1002-1005. [CrossRef] [PubMed]

25. Sehimi, H.; Akitsu, T.; Zid, M.F. Synthesis and structural study of tris(2,6-diaminopyridinium) bis(oxalato)dioxidovanadate(V) 2.5-hydrate. Acta Crystallogr. Sect. E 2019, 75, 680-684. [CrossRef] [PubMed]

26. Bain, G.A.; Berry, J.F. Diamagnetic Corrections and Pascal's Constants. J. Chem. Educ. 2008, 85, 532-536. [CrossRef]

27. Kominato, C.; Akitsu, T. Photoinduced molecular orientation of catalytic-like chiral azo-schiff base complexes in schiff base complexes in PMMA or laccase matrices. Lett. Appl. Nanobioscience 2015, 4, 264-270.

28. Frisch, M.J.; Trucks, G.W.; Schlegel, H.B.; Scuseria, G.E.; Robb, M.A.; Cheeseman, J.R.; Scalmani, G.; Barone, V.; Mennucci, B.; Petersson, G.A.; et al. Gaussian 09, Revision D.01; Gaussian, Inc.: Wallingford, CT, USA, 2009; p. 201.

29. Morris, G.M.; Huey, R.; Lindstrom, W.; Sanner, M.F.; Belew, R.K.; Goodsell, D.S.; Olson, A.J. AutoDock4 and AutoDockTools4: Automated Docking with Selective Receptor Flexibility. J. Comput. Chem. 2009, 30, 2785-2791. [CrossRef]

30. Gasteiger, J.; Marsili, M. Iterative partial equalization of orbital electronegativity-A rapid access to atomic charges. Tetrahedron 1980, 36, 3219-3228. [CrossRef] 
31. Morris, G.M.; Goodsell, D.S.; Halliday, R.K.; Huey, R.; Hart, W.E.; Belew, R.K.; Olson, A.J. Automated Docking Using a Lamarckian Genetic Algorithm and an Empirical Binding Free Energy Function. J. Comput. Chem. 1998, 19, 1639-1662. [CrossRef]

32. Sehimi, H.; Essghaier, B.; Barea, E.; Sadfi-Zouaoui, N.; Zid, M.F. Synthesis, structural study, magnetic susceptibility and antimicrobial activity of the first ( $\mu$-oxo)-bis(oxalato)-vanadium(IV) 1D coordination polymer. J. Mol. Struct. 2019, 1175, 865-873. [CrossRef]

33. Ben Moussa, O.; Chebbi, H.; Zid, M.F. Synthesis, crystal structure, vibrational study, optical properties and Hirshfeld surface analysis of bis(2,6-diaminopyridinium) tetrachloridocobaltate(II) monohydrate. J. Mol. Struct. 2019, 1180, 72-80. [CrossRef]

34. Brown, I.D.; Altermatt, D. Bond-Valence Parameters Obtained from a Systematic Analysis of the Inorganic Crystal Structure Database. Acta Crystallogr. 1985, B41, 244-247. [CrossRef]

35. Huang, H.; Sakurai, T.; Monjushiro, H.; Takeda, S. Magnetic studies of the trinuclear center in laccase and ascorbate oxidase approached by EPR spectroscopy and magnetic susceptibility measurements. Biochim. Biophys. Acta 1998, 1384, 160-170. [CrossRef] 